\title{
PAÍSES Y PAISAJES EN CANTO A SU AMOR DESAPARECIDO DE RAÚL ZURITA ${ }^{1}$ \\ COUNTRIES AND LANDSCAPES IN RAÚL ZURITA'S CANTO A SU AMOR DESAPARECIDO
}

\author{
Paula Miranda \\ Pontificia Universidad Católica de Chile, Chile \\ pmirandh@uc.cl \\ Roberto Ibáñez \\ Creative Writing in Spanish-M.F.A. New York University, U.S.A. \\ «- Cantando, cantando a su amor desaparecido».
}

RZ

\begin{abstract}
Resumen:
El presente artículo sitúa el sentido fundamental de Canto a su amor desaparecido (1985) de Raúl Zurita, en el contexto de las transformaciones que han sufrido las representaciones paisajeras y las poéticas del habitar en la poesía chilena, para demostrar que, a partir de la obra zuritiana, cambian para siempre las poetizaciones que se hacían de los países (como territorios) y de los paisajes y se instaura un nuevo paradigma para la cultura sobre paisajes y naciones. Se analizan, para demostrarlo, la materialidad y circulación del libro, la desaparición aparente de los países, la declinación y nuevo auge del canto poético, el diálogo amoroso y el reemplazo de la poética del habitar por una nueva concepción del paisaje, esgrimido aquí como método, para enfrentarse al horror, la violencia y la alteración perceptiva provocada por los actos de barbarie cometidos por la dictadura militar chilena, centralmente el de los detenidos desaparecidos.
\end{abstract}

Palabras claves: poesía chilena, paisaje, Raúl Zurita

\begin{abstract}
:
The article contextualizes the fundamental meaning of Raúl Zurita's Canto a su amor desaparecido (1985) in the transformations of landscape representations and the inhabiting poetics in Chilean poetry. The aim is to demonstrate that Zurita's work radically changes the poetization of countries (as territories) and landscapes. Thus a new paradigm for the culture of landscapes and nations arises. To demonstrate the rise of this paradigmatic change, the following aspects will be analyzed: the materiality and circulation of the book, the apparent disappearance of countries, the fall and surge of the poetic chant, and the amorous dialogue and the replacement of the inhabiting poetics for a new idea of landscape. This landscape grows as a method to face horror, violence, and the altered perception caused by the cruel acts committed by the Chilean military dictatorship, especially those regarding the detained and missing.
\end{abstract}

Keywords: Chilean poetry, landscape, Raúl Zurita.

Recibido: 30 de mayo de 2018

Aceptado: 17 de octubre de 2018

${ }^{1}$ Este artículo se ha realizado en el marco del Proyecto Fondap-CONICYT № 1510006 "Creación y consolidación del Centro de Estudios Interculturales e Indígenas (CIIR)”, del que Paula Miranda es Investigadora Asociada (2013-2018). 
Hasta los años 70, y en muchos casos, un número importante de poetas chilenos modernos había establecido una relación íntima y afectiva con la tierra en la que nacieron, fuese ésta el paisaje o el país, fuese el Valle del Elqui, el lluvioso sur, la cordillera de los Andes, Lebu o Licantén. Cualquiera fuese la forma que esta relación adquiría, desde la poesía modernista de Pedro Prado, los poetas habían estado casi subyugados al «peso de la tierra» (49) como decía Teillier y a sus morfologías naturales, aunque desde una pulsión más bien paisajística que territorial, pues privilegiaban, en ese vínculo con el entorno y sus morfologías naturales, la mirada estética, la subjetividad y el imaginario (Ansón 231).

Esta mirada, que era también fuertemente cultural, estaba atemperada por un sentido de pertenencia, que se basaba en la noción de identidad territorial, la que en muchos casos determinaba su biografía, sus contextos y sus responsabilidades públicas. Recuérdese por ejemplo la importancia del Chile campesino de Mistral, o el folklórico de Violeta Parra o la nación política del Neruda senador de la República. Esta identidad territorial los vinculó estrechamente con el concepto de nación moderna o de identidad nacional, claro que desde posiciones críticas y alternativas y siempre desde lugares específicos, ya fuesen naturales, rurales o urbanos. Pero, además, estos poetas crearon un espacio del habitar, en que el hogar de la infancia y la búsqueda permanente de lugares de arraigo resultaba fundamental. Muchos asimilaron el concepto de patria, más afectivo y telúrico, al espacio del habitar feliz y en muchos casos el acto poético les permitió fundar ese lugar. Decía Mistral:

Mientras fui criatura estable de mi raza o mi país, escribí lo que veía o tenía muy inmediato. Escribí como quien dice, sobre la carne caliente del poema... desde que soy criatura vagabunda, desterrada voluntaria, parece que no escribo sino en medio de un vaho de fantasmas. (Cómo escribo 13,30)

En ese camino, la representación subjetivada de lo nacional fue también fundamental: «soy un país hecho poeta» (12) decía De Rokha en su «Balada».

Pareciese que fuese la poesía la que mejor plasma artísticamente esa función humana de tener que significar, representar y darle sentido a los entornos, a los lugares físicos o imaginados en los que se nace y habita, esa capacidad que tan bien describió Sloterdjk, cuando pensó al «ser humano como una caja de resonancia que se templa, retempla y destempla según los espacios en que vive» (18). Diríamos que en Chile hay una naturaleza muy poderosa en términos de cómo ella determina los imaginarios y las 
experiencias, más todavía cuando esta naturaleza somete a quienes la habitan y de manera periódica a terremotos, tsunamis o erupciones volcánicas. Creemos que esa relación entre poesía y naturaleza es muy significativa en un país como Chile. Pero esta omnipresencia en la poesía también se debe a una «cultura paisajística» (Berque 23), acumulada en nuestra historia, a través de la experiencia directa con el entorno (ya sea natural, urbano o rural) o bien mediado por ideologemas estéticos o sociales (Bajtín 150). Nuestros poetas construyeron desde lo estético distintos modelos paisajeros, habiendo una relación algo menos mediada culturalmente en el caso de los poetas mundonovistas (Mistral, Pezoa Véliz, Prado o Reyes), algo más estetizante y experimental en el caso de Huidobro y otros vanguardistas (como Plonka) y definitivamente materialista, metafísica y telúrica en los casos de Neruda y De Rokha, sólo por pensar en algunos.

Pero no todo es lineal en las diacronías poéticas, pues fueron los mundonovistas quienes iniciaron en Chile la poesía paisajera, y el paisaje creacionista cubista del Huidobro de «Paisaje» de 1917 tuvo su base en el Huidobro mundonovista de 1912. Nuestros poetas combinaron esa suerte de temple o actitud de arrobamiento (experiencia de lo sublime frente a la naturaleza) con un riguroso estudio de estos entornos (Neruda y Mistral los que más), con una conciencia mítica y cosmológica y con una buena dosis de sentido de la vulnerabilidad, provocada por los grandes remezones naturales o políticos, bajo el sentido de lo hórrido. A esa representación paisajística, Rogerle ha llamado artealización in visu. Un fenómeno más reciente en esta relación social con el paisaje, sería el de la artealización in situ (15,35), en la que el artista agrega algo al paisaje, de una manera material. Aquí no sólo se inscribe por ejemplo la frase «ni pena ni miedo» de Raúl Zurita en el Desierto de Atacama, sino también el uso turístico que se realiza en Chile con las casas de nacimiento y muerte de nuestros poetas, incluida la propia casa de Nicanor Parra a través del proyecto «El litoral de los poetas»².

Pero algo distinto y definitivo ocurrió a partir de 1970, en esta relación y en su expresión poética. En coincidencia con la mutación cultural ocurrida en esos años y

2 El litoral de los poetas corresponde a un sector del litoral central de Chile, relevante tanto turística como culturalmente debido a la presencia de las casas de importantes poetas chilenos: de Pablo Neruda en Isla Negra, de Vicente Huidobro en Cartagena y de Nicanor Parra en Las Cruces. Diversas entidades locales han promovido un turismo cuya ruta imaginaria es el recorrido por las casas de estos poetas. Habría que señalar que al menos la localidad de Isla Negra desarrolla toda su actividad turística en torno a la casa de Pablo Neruda. 
especialmente a partir del Golpe de Estado de 1973, la poesía sufrió una amputación estética, sobre todo en el ámbito de su relación con esta conciencia paisajera y con la obsesión territorial. Nunca más el poeta se volvería a relacionar con los entornos desde un deseo y una poética del habitar, desde un afán identitario y una postura ideológica unívoca, ya sea estética o social. Nunca más en poesía estaríamos frente a la cosmología estética de un Canto General (1968), de un Poema de Chile (1967), de una Epopeya de las Comidas y Bebidas de Chile (1949), de un Horizon Carré (1917) o de un Altazor (1931).

A partir de los años 70 no solo tiende a disminuir temática o perceptivamente esta relación «sujeto-entorno» en poesía, sino que ese mismo entorno, industrializado e hipermediático, con más crecimiento económico, pero también con más desigualdad, tenderá a hacer desaparecer a los países —en lo que estos tienen de únicos y diferentesy también a la propia poesía, una poesía que aquí ya no será inspirada por los países, esa «carne caliente del poema» (Cómo escribo, 13, 30) que movilizaba a Mistral, sino probablemente por «países» ya «muertos», como los que percibe Zurita.

Nos parece que la obra que mejor encarna este proceso es Canto a su amor desaparecido (1985) y que ella representa una inflexión en el periplo que va desde Purgatorio (1979) a La vida nueva (1993).

Proponemos aquí que Raúl Zurita aspira a una nueva cultura paisajera, una que se esgrime como método para enfrentar la violencia extrema y la alteración perceptiva y que tendrá múltiples realizaciones: por eso el suelo se trasmuta en cielo y las cordilleras marchan por el mar. Los modelos paisajeros de Zurita son múltiples y provienen de distintas culturas, siendo la cultura nacional sólo una más entre muchas, aunque el referente central sean las morfologías naturales chilenas. Algo muy distinto de lo que ha sido el paisaje en términos poético-históricos, pues en Zurita no se persigue ni el goce estético ni se busca el disfrute sensorial, más bien se opta por un sublime del cual se será víctima o frente al cual se expresará compasión: «para que en toda la patria se escuche ahora el balar de nuestras propias almas sobre esos desolados desiertos miserables» (Zurita, Purgatorio $35)$.

El proyecto de los años 80 de Zurita resulta así fundamental para el giro definitivo que sufrirá la representación paisajística y territorial en poesía y en el arte en general. Proponemos que, para esta etapa, la poesía de Zurita revitaliza entre nosotros la idea de los 
paisajes sublimes, ya no contemplados ni cantados, sino culturizados y bajo imágenes de lo hórrido y también del horror, debido a ello, hay una preeminencia del purgatorio, el nicho y el desierto. Lo sublime estará también asociado a la inmensidad: mares que se abren, montañas que marchan, cielos invertidos. La meta final es la creación de un paraíso, sólo posible en la tierra y de manera colectiva. Recuérdese sí que pairidaeza es originalmente, en persa antiguo, un cercado, un lugar rodeado por murallas, un jardín a resguardo de posibles amenazas y desbordes. Zurita ha reflexionado mucho sobre qué entiende por paraíso, y algo hay allí de ese sentido antiguo del lugar resguardado, aislado y que hay que construir.

Creemos que el paisaje es, en Zurita, una estrategia para enfrentarse a la historia de la violencia, a la cultura del exterminio y la derrota. Por eso, cuando atravesamos Anteparaíso (1982) o La Vida Nueva (1994), resuenan realidades más amplias y no suscribimos la idea de que todo tenga que interpretarse en clave dictatorial o mental: hay allí diversas eras geológicas, memoria de glaciaciones y grandes catástrofes, naturales e históricas, cosmologías de muchas latitudes (la tierra y el cielo consustanciados pertenecen al Popol Vuh, modelo mítico que también inspiró a Neruda).

Para Benoît Santini el paisaje surge en la poesía de Zurita de referentes reales y desmesurados (chilenos), pero se va deformando y transformando en «alegoría de los grandes sentimientos humanos» (2) que específicamente expresaría las «experiencias traumáticas y las desventuras de los hombres» (Id. 15). Por su parte, Alejandro Tarrab, plantea que el desierto de Inri (2004) se transfigura debido a la fuerza del espejismo y de las ansias del propio ser (15). Para Rodrigo Cánovas, en cambio, el paisaje le sirve al Zurita de Purgatorio (1979) como una forma estética para denunciar la censura y la represión impuestas por la dictadura en Chile, a través del recurso ahora del delirio (82).

El proceso de crisis y revisión aparece con gran radicalidad en Canto a su amor desaparecido (1985) (en adelante CASAD). En él se pone en evidencia la crisis total de la nación moderna, sobre todo en su dimensión simbólica y estética, pero también el vínculo estético con los entornos, o sea, la noción de paisaje. Zurita termina de clausurar (algo de esto ya está obviamente en Nicanor Parra y en Enrique Lihn) muchas de las configuraciones identitarias del periodo anterior: como el espacio del habitar, la infancia espacializada, la sensorialidad real en contacto con los espacios, la memoria territorial (el 
tuwün mapuche), incluso cierta trascendencia vinculada a ella, pero agrega otras, muy sintomáticas en términos epocales: frente a la clausura y la derrota, Zurita expresa su desesperación hiriendo su cuerpo físicamente (quema su mejilla, se masturba en el baño de la galería Cal, en donde se realizaba la exposición de Juan Dávila, «no puedo más», y se lanza amoníaco en los ojos), intentando mutilarse en el plano corporal, para liberarse en el plano social. En ese gesto, Zurita constata la fractura, pero evidencia también un compromiso, una militancia, una postura o visión de mundo de la que los poetas posteriores a él estarán en general exentos. Uno pensaría que incluso durante la dictadura chilena (1973-1990), esa tendencia hacia el sentido comunitario y hacia la resistencia se mantuvo en algunas personas o grupos, en especial entre los artistas, de ahí cierto tono utopista o mesiánico que a veces embarga al sujeto. Zurita reacciona entonces, frente al horror, con una triple mutilación de una gran violencia simbólica: la de la propia poesía, que decreta la muerte definitiva de los países (en $C A S A D$ ); la de países que decretan la muerte de los poemas y la de un poeta constatando su «poesidio» ¿Cómo se logra esto? Yendo más allá del poema, de ahí la flagelación ya descrita y la inscripción de su propia escritura en estos países físicos que pueden desparecer en cualquier momento, como sus palabras en los cielos de Nueva York o su «ni pena ni miedo» en el desierto de Atacama, manifestaciones que han sido estudiadas bajo el concepto de land art o earth art, por críticos como Juan Soros (2012), pero que Zurita prefiere pensar solo como continuidad de su proyecto poético y no como land art, según entrevistas concedidas a Benoît Santini en Lyon y a Paula Miranda. El poeta expresa enfático:

Yo digo que no es land art, porque el land art es fundamentalmente un arte abstracto, que se apoya sobre el soporte de la tierra y sobre los paisajes, pero es fundamentalmente abstracto. Esto parte de la palabra, parte del poema, no hago nada que no sea un poema, con otros soportes, y a la vez es visual, claro, porque interviene el paisaje, pero el paisaje también intervenido por la palabra en un poema ${ }^{3}$.

Refuerzan esta idea los registros fotográficos de muchas de esas intervenciones «in situ», los que son incorporados como parte de los iconotextos de varios de sus libros.

\footnotetext{
${ }^{3}$ Entrevista realizada por Paula Miranda y Roberto Ibáñez a Raúl Zurita el día 6 de enero de 2016 en su casa. (Inédita).
} 
«Artealización» in situ le llamaríamos a estos fenómenos en la lógica de los paisajes, o sea, la inscripción radical y fervorosa de la propia obra en la realidad física de los lugares. Por eso Zurita manifiesta con tanta seguridad que sus palabras más íntimas son las escritas en «La Vida Nueva», en el cielo de Nueva York, junto al verso «ni pena ni miedo», escrito en el desierto, y que aquel libro que nunca hubiese querido tener que escribir, sea justamente Canto a su amor desaparecido.

Nuestra argumentación la realizaremos en torno a los siguientes ejes: la desaparición sólo aparente (o transitoria) de los países; la declinación y nuevo auge del canto poético (canto asociado al amor) y, por último, el reemplazo de una poética del habitar (pertenencia y origen) por una cultura paisajera como método.

\section{Materialidad del libro}

Pese a ser un solo extenso poema, CASAD (1985) se estructura a través de secciones completamente distinguibles entre sí. Abre el poemario la apelación que, como veremos, realiza una voz al propio Zurita.: «Ahora Zurita...»(7). Estas palabras iniciales no sólo inauguran $C A S A D$, sino que también establecen una duda fundamental que atraviesa el libro. «Si de puro verso y desgarro» (Ibid.) Zurita ha logrado entrar en aquel espacio donde se podrían resolver los conflictos ocasionados por la violación de los derechos humanos, la voz inquiere sobre la posibilidad de encontrar aquellos cuerpos desaparecidos a través de la poesía. Luego de estos versos, y también como paratexto, se encuentra la dedicatoria del libro. Si bien creemos que estas dos secciones simulan funcionar como paratextos, consideramos que son fundamentales para la lectura del poemario y que forman parte de la obra misma, pues ésta cambia radicalmente sin ellas. Orientan la lectura y son imprescindibles, finalmente, en la estructura general de la obra: la primera pregunta «¿tú puedes decirme dónde está mi hijo?»(Ibid.) es respondida al final del poemario con un «sí, dice» (29) en gran tamaño de letra. Esta frase final aparece recién en la $4^{\text {a }}$ edición (1987). En la primera (1985), en cambio, el cierre está dado por «Así sonó entonces el Canto/ a su amor desaparecido» (29) y en el manuscrito del fondo Cruz, el «sí dice» aparece tachado y secundando otra frase final «y todos, quizás porque hermanos, lloraban» ${ }^{4}$. De alguna

\footnotetext{
${ }^{4}$ Copia de los manuscritos del fondo Cruz fueron facilitados por el estudioso Benoît Santini para este trabajo.
} 
manera, este cambio permanente al final del libro permite pensar en una respuesta que parece no definitiva ni fija, si no abierta y cambiante, como esa terrible incertidumbre que provoca la desaparición forzosa de personas.

De este modo, en la primera edición, desde la página once a la diecisiete se encuentra la primera sección de $C A S A D$. La presentación de los versos es atípica y mezcla prosa poética, versos y versos presentados a través de guiones, a la manera de diálogos o voces que se superponen unas con otras. A pesar de esta mezcla, jamás un verso excede la delimitación de las líneas y todos mantienen su forma de bloque. Aquellas subsecciones que son presentadas en verso se asemejan y adelantan los dibujos de los nichos que se leen más adelante. Justamente, aquella sección es la que precede a la ya descrita. A través de dibujos que figuran nichos, visitamos los galpones 12 y 13, en los que yacen los países muertos. Esta sección mantiene un orden visual estricto, en el que en cada tumba hay un país, una región, un paisaje e incluso un caudillo revolucionario (Sandino, por ejemplo). Junto a esta sección, muy relacionado pero con unidad propia, se encuentra el dibujo que el mismo Zurita realiza de los cuarteles 12 y 13. La sección «Canto de amor de los países» concluye el poemario y cierra la estructura muy cuidada de él. La presentación de los versos es también atípica: se basa en preguntas y respuestas, además de versos en tono exhortatorio. Este tono está en sintonía con la voluntad del canto que existe en esta sección. Finalmente, otro paratexto cierra ya el libro: «Así sonó entonces el Canto/ a su amor desaparecido» (29).

Otra de las particularidades del libro es su gran formato. La primera edición exhibe treinta y seis $\mathrm{cm}$. de alto por veinticinco de ancho, lo que contrasta con sus reducidas treinta y dos páginas, semejando un block de dibujo. En ediciones posteriores, no obstante, esta medida se reduce. Ponemos la mirada aquí, pues este gran formato está en directa relación con su intención fundamental: la voluntad de que el texto alcance una materialidad lo más cercana posible a los nichos que describe, de que exceda el libro, de que retorne a lo real. Basta con pensar que el verso «Todo mi amor está aquí y se ha quedado pegado a las rocas, al mar y a las montañas» (Id.12) se encuentra hoy grabado, encabezando el Memorial del Detenido Desaparecido y del Ejecutado Político, erigido en el patio 102 del Cementerio General de Santiago de Chile. O sea, el gran formato buscaría de alguna manera monumentalizar la sentencia de que el amor prevalecerá, pese a todo. Otros libros de Zurita 
exceden también el tamaño frecuente de un libro de poesía (Anteparaíso, El amor de Chile, La Vida Nueva). Pareciera ser que la experiencia que genera o motiva estos libros supera las limitaciones del libro tradicional. Como Neruda cuando exigía «Libro, déjame libre» (Odas elementales, 135). Hay que pensar las escrituras materiales no sólo como aquellas palabras cruzando el cielo o el desierto, sino también como los libros mismos que se ven obligados a aumentar sus dimensiones, pues de otra manera serían incapaces de contener aquella extrema e indecible experiencia de la desaparición forzosa.

\section{Desaparición de los países y algo más}

Pero ¿qué desaparece definitivamente en $C A S A D$ ? Los desaparecidos no son sólo las víctimas más atroces de la dictadura, aquí han sido detenidos y desaparecidos los propios países y los continentes, sus historias y memorias, sus paisajes, morfologías y territorios. Se consigna con frialdad (la frialdad del nicho, la distancia del hablante) el deceso definitivo de continentes y países. Esa desaparición del sentido de país como una comunidad política imaginada, es reemplazada por lugares de negación: galpones de cemento, nichos y desiertos, los que además geometrizan la página. En uno de los nichos se lee: «Nicho Paraguay. En cuartel 13, debidamente señalizado. También masacre entre países, guerras del Chaco, condominio y padecimiento. Yace ahora alambrado en nicho, pasadizo y tumba» (20). Aquí los lugares son enumerados sintéticamente en sus rasgos fatalistas o funerarios esenciales, bajo un tono que se asemeja al laconismo profético del Libro del Chilam Balam de Chumayel (1992), dando un tono también mítico y despersonalizado a la enumeración fúnebre. El único espacio que diverge en parte de esta hegemonía de la muerte-es la imagen del desierto, pues el hablante alude a «desiertos de amor». El desierto tenía ya en Purgatorio (1979), la connotación positiva de patria, de lugar que contiene y protege al ser (79).

La necrópolis de Canto a su amor desaparecido, tan bien estudiada por Edmundo Garrido, es lo que se instala como la poética del habitar $(161,171)$. La desaparición de los países es reemplazada fuertemente por la heterotopía del cementerio. En CASAD, el desierto no es un lugar geográfico, sino geométrico, como indica Waldo Rojas, que además semantiza a los propios sujetos que habitan en él bajo el signo de la desertitud $(63,74)$. En 
Zurita, por tanto, se ha perdido el vínculo con los entornos paisajeros, pero en su lugar se ha puesto una necrópolis que hará memoria de su devenir.

En CASAD (1985), Zurita pone en evidencia la crisis total de los países. Hay ternura y compasión frente a éstos que son ahora cadáveres dispuestos en nichos y prima por ello un cierto tono utópico o mesiánico, pero en clave de fracaso. A continuación de los nichos en que han sido dispuestos los países, se presenta el texto «CANTO DE AMOR DE LOS PAÍSES» (27), el que parece ser una exhortación de los propios países hacia el cantor. Los países ya muertos (en los manuscritos del fondo Cruz este texto figura bajo el nombre «Canto de amor de los países muertos» ${ }^{5}$ ) parecen confirmar su condición de tales (abandono, muerte), pero lo hacen bajo la forma de una exhortación interrogativa que dialoga con el canto de la noche, una noche que canta bajo la tierra. Esa interrogación le pide al canto que aparezca: «iAparece entonces!»(27). Este llamado final se lee con más claridad si se le compara con el manuscrito de $C A S A D$, en que se explicita que el apelado es el «pájaro cantor», el mismo poeta, un poeta que tiene todo el «lloro mío». Incluso aquí la aparición es más radical: «Resucita, entonces», se lee, lo que en la primera edición se convertirá en: «iAparece, entonces!»(Ibid.).

\section{Canto, desencanto y reencantamiento}

Al parecer entonces, será a través del canto que todo podrá redimirse, incluso el amor de los desaparecidos. CASAD intertextualiza obviamente la larga tradición de la poesía asociada al canto, pero también la desmantela. Para Mistral, sólo la canción se ensangrienta para aliviarla y es una herida de amor que le abren las cosas. Cantos rituales hay en Ternura (1924), pero sobre todo en Tala (1938) y en Poema de Chile (1967). El canto quechua transfigura realidades y el mismo sujeto femenino vuelve a arder en el fuego solar de las antiguas culturas indígenas del continente a través del canto. Neruda opta por un Canto General, pero también particular y personal: «aquí dejo mi canto» (492). Pero en Zurita, éste es un canto fúnebre, una elegía, cuya mayor connotación es la que lo vincula con los desaparecidos a través de un lamento colectivo. Existen cantos fúnebres antiquísimos y modernos, y Zurita no desea renunciar a esa larga tradición. La más lejana es la de los cantos fúnebres del Popol Vuh o de la tradición criolla chilena, en la figura del

${ }^{5}$ Del cual Benoît Santini nos facilitó una copia. 
canto a lo divino o de la cueca larga. La más cercana es la de los cantos de Dante, la de los Cantares de Pound y sobre todo la del Canto General. Zurita desea remontar ese canto, porque, según nos dice en una entrevista radial, ese canto no era suficiente para los tiempos de dictadura ${ }^{6}$. Ese Canto (General) resuena en el propio Zurita como un eco desvalido de una promesa que nunca pudo cumplirse o cuyo cumplimiento fue exterminado antes de realizarse. Pero hay más cantos, no sólo los de la poesía: está el canto de la canción popular. Zurita nos confiesa que cuando está escribiendo $C A S A D$, está impresionado con la aparición en Chile de dos grupos de rock chileno: Los Prisioneros y Los Pinochet boys. De ahí que el nombre de los primeros aparezca en los msBNC y del fondo Cruz encabezando el texto referido al momento exacto en que los amantes son sepultados y desaparecidos en $C A S A D$, aunque en la primera edición este nombre haya desaparecido. Hemos sido testigos de ver a Raúl Zurita «rockeando» junto a «González y los asistentes», y podríamos asegurar que es un poeta rock. Aunque él nos aclare, a través de una entrevista escrita, que es un poeta folk: le «alucina» el folklore y el neofolklore boliviano y argentino, sobre todo y claramente la Violeta Parra de las Últimas composiciones. Y entre todas estas posibilidades y tonos que la canción le otorga, él opta por cantar la cólera, se reconoce, según su propio testimonio, en el «Canta, oh Diosa, la cólera de Aquiles» (1) de Homero.

Pero al escuchar y ver a Raúl Zurita en sus lecturas y presentaciones en vivo, especialmente cuando su recitación de CASAD se une al trabajo de músicos, hemos tenido la certeza de que una de las formas en que funciona más intensamente el tono violento y a la vez sublime de $C A S A D$ es con la propia voz de Zurita. Sus interpretaciones, que no son musicalizaciones de sus poemas, sino recitaciones intensificadas por la música; resultan imprescindibles a la hora de pensar en el sentido poético que hay en su «Canto».

En $C A S A D$ se preserva cierta sonoridad tonal y sobre todo coral, pues son muchas las voces que hablan en su interior. Existe una primera voz, con la que se inicia el canto, quizás la de un público que es a la vez padre o madre del detenido desaparecido, que recrimina férreamente al poeta, por su imposibilidad de dar respuestas concretas: «Ahora Zurita -me largó- ya que de puro verso y desgarro pudiste entrar aquí en nuestras

\footnotetext{
6 Entrevista realizada por Paula Miranda a Raúl Zurita, 02 feb. 2015, Programa Holojazz, Radio
} Universidad de Chile. 
pesadillas; tu puedes decirme dónde está mi hijo» (7). A esa voz, le sucederá la propia del poeta, quien realiza una dedicatoria ficticia a los sobrevivientes, pero bajo una modalidad ambigua en la que se traslapan víctimas y victimarios:

\section{A la paisa}

A las madres de la plaza de mayo

A la agrupación de los familiares que no aparecen

A todos los tortura, palomos del amor, países chilenos y asesinos (Zurita, Canto 9)

Los dos términos que enmarcan la dedicatoria nos remiten a país. El termino paisa no se utiliza en Chile, pero en otros países latinoamericanos designa al habitante del campo, bajo connotaciones de amistad y compadrazgo, demostrando el vínculo de la palabra país con un término que implica vínculo emotivo y colectivo con la tierra en que se ha nacido. Esa noción comunitaria es amputada por las desapariciones tanto en Chile («agrupación» que remite a la Agrupación de Familiares de Detenidos Desaparecidos y Ejecutados Políticos) como en Argentina («Madres de la Plaza de Mayo»). Por eso la dedicatoria remata en una nueva y ambigua noción de país, bajo la imagen «países chilenos y asesinos», cancelando definitivamente y a través de esta antítesis, la posibilidad de pensarnos como país. Esto es reforzado por la imagen de la tortura, personificada en la expresión «a todos los tortura, palomos del amor», bajo antítesis y ambigüedad máximas. En estas agrupaciones antitéticas se iguala a los «tortura» (que pueden ser igualmente torturadores y torturados) y a «los palomos del amor», reminiscencia del folklore andino.

Esa ambigüedad temática inicial también se proyecta en la estructura ambivalente de $C A S A D$, por cuanto en el libro son también muy importantes los recursos gráficos: los países son, antes que poetizados, dibujados en el formato de nichos, a la manera de un mapa de la necrópolis continental. El coro se continúa en la estructura de tres voces que circularán acotadas a través de todo el libro, dos de ellas de muertos que monologan entre sí. Huellas del canto se expresan en la extrema oralidad de los discursos de los muertos, en su registro conversacional confidente, que mezcla la tensión de la violencia, junto a la distensión de la poesía paisajera: «Como te llamas buen culo bastarda chica, me preguntaron (Pero mi amor te digo ha quedado adherido a las rocas, al mar y a las montañas)» (13). El canto se expresa asimismo en el sonido onomatopéyico, extenso hacia 
el final del poemario, con ecos de los Cantos de Altazor o el viaje en paracaídas (1931). En la fuerza performativa de las lecturas en vivo de parte del poeta, se fortalece la idea de la preeminencia del canto, por sobre la escritura. Más aun, la de un canto colectivo y transhistórico, cuya realización máxima se efectúa gracias a la fuerza transfiguradora del amor. Un canto que perdurará ya no en la forma de la canción, sino en la de los propios fragmentos del paisaje: «Pegado, pegado a las rocas al mar y a las montañas» $($ Id.12, 14), o sea más allá de la canción y de sus amantes, aunque gracias a ellos.

Porque uno de los motivos fundamentales de CASAD es la relación de dos enamorados que no pueden encontrarse, sino solo a través de la eternidad de «las rocas», «el mar»y las «montañas». En medio de esta necrópolis que es $C A S A D$, lo que prima es la imagen de los enamorados en el nicho de la muerte, tratando de rescatar el amor (algo hay aquí del soneto del siglo XVII «Amor constante más allá de la muerte» de Quevedo). El diálogo ocurre en el sitio de la muerte, al igual que en los «Sonetos de la muerte» de Mistral, pero aquí nadie puede rescatar a nadie. Recordemos el primer soneto mistraliano: «Del nicho helado en que los hombres te pusieron /te bajaré a la tierra» $(124,125)$. Si Mistral realiza aquí un ritual de restitución del amado a la vida eterna, en la tierra, en $C A S A D$ se decreta la imposibilidad de encontrar al otro, pero la posibilidad, abierta gracias al canto, de permanecer más allá de la muerte. Las voces de los amantes no podrán reencontrarse, pero de todas maneras el amor prevalecerá «Murió mi chica, murió mi chico, desaparecieron todos. Desiertos de amor» (12).

Con todo, CASAD es un libro que supera sus propias fronteras. Zurita no sólo considera el amor de los amantes, sino el amor expresado en y desde todas las cosas y personas. «El amor son las cosas que pasan» (14). La tortura y desaparición de los cuerpos también atenta contra su amor: «Nuestro amor muerto no pasa»(Ibid.). En ese sentido entendemos la permanencia del amor a través del canto, pues la única posibilidad de superar aquella desaparición es a través de ése. Así, la plegaria final del libro dice: «levántate y lárgale de nuevo su vuelo y su canto/ al que sólo por ti paisa vuela, canta y toma forma/ devuélveselo a este el más soñado y llorado/ desaparecido del amor/ palomo y malo» (Id. 27). La desaparición, asociada a los «desiertos de amor», y la lucha por superarla abarca tanto a los amantes como a los padres, a los hijos, a la paisa, a la comunidad total. 


\section{Más allá de Canto a su amor...}

En definitiva, en $C A S A D$ la herida social y personal que significa la desaparición de los países y de los amantes implicará esgrimir modelos paisajeros desde la alucinación, el desvarío, la desesperanza y, en algunos momentos, con breves vislumbres, desde la esperanza. Por ello y necesariamente se intensifica también en el plano de los referentes paisajeros, una intensa tradición de intertextualidad: citas, auto-citas, reescrituras y transtextualidades. Los sustratos son los Salmos bíblicos, el profeta Isaías, las películas escatológicas, el discurso amoroso, las canciones populares, la jerga militar, las imágenes culturales del paisaje chileno, incluso el Himno Nacional de Chile (recurso este último que ya había sido utilizado productivamente en Anteparaíso).

Por eso nos atrevemos a proponer que, en $C A S A D$, el paisaje ha cambiado su conceptualización, no sólo por ser aquí expresión de los dolores y las pasiones humanas (en él Zurita ve el rostro y el color y el dinamismo del cuerpo humano), sino porque el paisaje se esgrime como un método, que sigue conteniendo al país (en el sentido de territorio y de nación), pero que lo supera ampliamente, productivizando la fuerza simbólica y utópica del paisaje en oposición a la idea más coyuntural de país. Un método que permite entonces descomponer el país y las morfologías naturales del país, para proclamar una única salvación: aquella simbolizada por la eternidad del canto, la permanencia de la naturaleza y del amor adherido a ella. El paisaje aquí ha sido relativizado en su fundamento: no es naturaleza mirada y valorada; sino que el paisaje mira y se compadece de la condición humana; no es arrobamiento ante lo sublime, sino que, frente a la reducción-nicho a que han sido sometidos los países, al horror al que ha sido expuesta la condición humana, la naturaleza se libera, vuelca y dinamiza sus coordenadas y referentes, con la finalidad de compadecer a esos mismos seres humanos. Y es justamente debido a esto, a estas estrategias, que el paisaje es por primera vez en nuestra poesía, profundamente histórico y analítico y se excede siempre a sí mismo: sus propios límites, su autoría, sus modelos paisajeros y sobre todo el espacio libresco y cultural en que inserta su obra. Por eso, este libro que el autor nunca hubiese querido tener que escribir, vive a través de uno de sus versos: «Todo mi amor está aquí y se ha quedado pegado a las rocas, al mar y a las montañas», inscrito en el frontis del Memorial del Detenido Desaparecido y del Ejecutado 
Político, y resguardando bajo esa frase-mantra y ritual, el doloroso listado de cientos de detenidos desaparecidos (a la izquierda del memorial) y de ejecutados políticos (a la derecha del mismo) dispuestos en listados (nombres y fechas de desaparición o asesinato) que son como nichos. El memorial fue inaugurado el año 1994. Dos rostros, uno masculino y otro femenino, fusionados en rocas y de grandes dimensiones, han sido dispuestos a cada lado del mismo. Esos rostros permanecen con los ojos cerrados y sólo la poderosa frase de Zurita los vuelve a la vida una y otra vez. Más significativo todavía resulta el hecho de que, algunos años después de la inauguración del memorial, se haya tomado la decisión de borrar el nombre de Raúl Zurita de su frontis, para convertirse ahora en un verso anónimo, que hubiese podido ser dicho por cualquiera de los cientos de víctimas que en ese memorial aún no han podido terminar de morir.

\section{Bibliografía}

Ansón, Antonio. “Territorios y paisajes. Modelos para pensar fotografía y literatura, tal vez soñar”. Paisaje y territorio. Ed. J. Maderuelo. Madrid: Abada, 2008. 231.

Bajtín, Mijaíl. Teoría y estética de la novela. Madrid: Taurus, 1989.150.

Berque, Augustin. El pensamiento paisajero. Madrid: Biblioteca Nueva, 2009. 23.

Cánovas, Rodrigo. "Zurita chilensis: nuestro dolor, nuestra esperanza". Literatura chilena y experiencia autoritaria. Ed Enrique Lihn, R. Zurita y J. Radrigán, Ictus . Santiago, Chile: FLACSO, 1982. 82.

De Rokha, Pablo. "Los Gemidos”. Antología (1916-1953). Santiago, Chile: Multitud, 1954. 12.

Garrido, Edmundo. "Construir una ciudad para la memoria: Canto a su amor desaparecido, de Raúl Zurita". Revista de filología románica (2008): 161-171.

Homero. Ilíada. Madrid: Gredos, 1982.1.

Mediz Bolio, Antonio (Trad.). Chilam Balam de Chumayel. Literatura Maya. Madrid: Ed. Historia 16. Y en M. de la Garza, Biblioteca Ayacucho, 1992. 217-185.

Miranda, Paula. Entrevista Raúl Zurita, Programa Holojazz, Radio Universidad de Chile, Chile. 5 de febrero 2015.

Mistral, Gabriela. "Cómo escribo". Prólogo a Todas íbamos a ser reinas. Santiago, Chile: Fondo Escolar, 1975. 13-30.

Mistral, Gabriela. "Sonetos de la Muerte”. Desolación. Santiago, Chile: Andrés Bello, 1979. 124-125.

Neruda, Pablo. Canto General. Buenos Aires, Argentina: Losada, 1968. 492.

Neruda, Pablo. Odas elementales. Santiago, Chile: Pehuén, 2005. 135.

Popol-Vuh. "Las antiguas historias del Quiche". Literatura Maya. Madrid: Ed. Historia 16, Y en M. de la Garza, Biblioteca Ayacucho, 1992.

Roger, Alain. Breve tratado del paisaje. Madrid: Biblioteca Nueva, 2007. 15-35.

Rojas, Waldo. "Raúl Zurita: ¿A las puertas de la esquizopóiesis?”. Poesía y cultura poética en Chile: aportes críticos. Santiago, Chile: Universidad de Santiago, 2001. 63-74. 
Santini, Benoît. El cielo y el desierto como soportes textuales de los actos poéticos de Raúl Zurita. Revista Laboratorio 1 (2009): 2.

http://revistalaboratorio.udp.cl/num1_2009_art6_santini/

Sloterdijk, Peter. Esferas. Madrid: Siruela, 2003.18

Soros, Juan. "Blurring the boundaries between land art and poetry in the work of Raúl Zurita". Review Literature and Arts of the Americas 45. 2 (2012): 227-235.

Tarrab, Alejandro. "INRI, la obsesión de tallar paisajes". INRI. Ed. R. Zurita. Madrid: Visor, 2004. 15

Teillier, Jorge. "Los poetas de los Lares". Boletín de la universidad de Chile 56 (1965): 49 Zurita, Raúl. Purgatorio. Santiago, Chile: Universitaria, 1979.

Zurita, Raúl. Canto a su amor desaparecido. Santiago, Chile: Universitaria, 1985.

Zurita, Raúl. Canto a su amor desaparecido. Santiago;Chile: Universitaria, 1987. Zurita, Raúl. Entrevista. Paula Miranda y Roberto Ibáñez. Sin publicar, enero 2016. 